$-282-$

THE EFFECT OF INTRACARDIAC BLOOD VOLUME ON SURFACE QRS AMPLITUDES

Iku Toda, Toshiyuki Takahashi, Hiroshi Satoh, Kiyoshi Kawakubo, Takashi Serizawa, Yoshiyuki Hada, Masahiko Iizuka, Tsuguya Sakamoto, Saburo Mashima, Tsuneaki Sugimoto

The 2nd Department of Internal Medicine, Faculty of Medicine, University of Tokyo

The effect of intracardiac blood volume on surface QRS amplitudes were studied by using the lower body positive and negative pressure device. Eleven cases including 6 old myocardial infarction, 3 angina pectoris patients were placed in the device. The pressure in the device was changed stepwisely from +20 to $-40 \mathrm{mmHg}$. Duration of each step was $3 \mathrm{~min}$. Frank lead electrocardiogram and M-mode echocardiogram was recorded simultaneously. QRS amplitudes on each lead, left ventricular end-diastolic dimension (LVDd), end-systolic dimension (LVDs) and distance from the chest wall to the interventricular septum were measured at each step.

During the study, neither anginal pain, ischemic electrocardiographic change nor conduction disturbanes were observed. At pressure of $+20 \mathrm{mmHg}$, both LVDd and LVDs increased significantly $(55.0 \pm 10.3$ vs $57.2 \pm$ $10.0 \mathrm{~mm} \mathrm{p}<0.05$ and $39.7 \pm 13.0$ vs $41.1 \pm 12.8 \mathrm{~mm}$ $\mathrm{p}<0.01$ ), while the QRS amplitudes of $X$ and $Z$ lead decreased slightly. Heart rate remained unchanged and the distance between the chest wall and the heart did not show significant change. At the pressure of -40 $\mathrm{mmHg}, \mathrm{LVDd}$ and LVDs decreased $(55.0 \pm 10.3$ vs 51.9 $\pm 10.9 \mathrm{~mm} \mathrm{p}<0.01$ and $39.7 \pm 13.0$ vs $38.4 \pm 13.9 \mathrm{~mm}$ $\mathrm{p}<0.1$ ), while the QRS amplitudes tended to increase on all leads (X $16.5 \pm 4.0$ vs $17.5 \pm 4.8 \mathrm{~mm}, \mathrm{Y} 8.7 \pm 4.2$ vs $9.6 \pm 5.0 \mathrm{~mm} \mathrm{p}<0.1, \mathrm{Z} 12.5 \pm 6.8$ vs $14.6 \pm 7.1 \mathrm{~mm}$ $\mathrm{p}<0.01)$. Heart rate was increased $(67.1 \pm 9.1$ vs 75.4 $\pm 9.5 / \mathrm{min} p<0.01)$ and the distance between the chest wall and the heart was increased $(40.8 \pm 8.7$ vs $42.9 \pm$ $8.2 \mathrm{~mm} \mathrm{p}<0.05$ ).

Thus, the diminution of intracardiac blood volume was found to be accompanied by the increase of QRS amplitudes on all leads. Some factors such as the changes of lung conductivity resulting from the decrease of pulmonary blood volume should be considered as the mechanism of alteration of surface QRS amplitudes.

$-283-$

THE CLINICAL STUDIES OF BODYSURFACE ISOPOTENTIAL MAPS IN THE NORMAL AGED

You Nakao, Hiroyuki Yoshida,

Ritsuko Terasaka, Katsushi Matsubara,

Hitoshi Matsubara, Kensuke Imataki,

Fumio Ihoriya, Haruki Nagahana,

N. Yamada, Daiji Saitou,

Shoichi Haraoka

The First Department of Internal Medicine, Okayama University Medical School

The body surface isopotential maps (maps) at 87 lead points were obtained. Maps from 296 normal subjects from 20 to 81 years old were analized comparatively among six groups (Male: Young 20-39 years old $\mathrm{n}=41$, midle $40-59$ years old $\mathrm{n}=52$, Old $60-81$ years old $n=59$, Female: Young $n=43$, midle $n=42$, old $\mathrm{n}=59$ ).

With increasing age, the following changes observed: 1 , On mean maps at the time of $10 \mathrm{msec}$ from the QRS initial, the maximum point shifted lower and the minimum higher; 2 , At $30 \mathrm{msec}$, the amplitude of the maximum decreased on the left anterior chest in males, while it increased in females; 3 , The maximum potential of QRS maps on each lead (Rmax V) slightly decreased on the antero-superior chest in males, while it efficiently increased on the area from the left anterior chest to the left back in females; 4 , The minimum potential ( $\mathrm{Smax} V$ ) became shallow; 5 , The sex difference of $R \max V$ become smaller; 6, The maximum voltage in $R \max V$ (Rmax Voltage) decreased in males, while it increased in females. It was considered that the potential of $\mathrm{R} \max$ voltage was affected by heart size and impedance of lungs. In addition, it was influenced by the breast in females.

On ST and T maps, significant sex differences were admitted among every age group.

On this study, the significant differences of maps between the aged and the younger groups were observed. Therefore careful considerations for age and sex should be taken in clinical use of maps in the aged.

\section{$-284-$ ESTIMATE ON SEVERITY OF LEFT ATRIAL OVERLOAD BY BODY SURFACE MAPPING} Onishi, Etsuko Tanaka, Shigeki Inaba, Jun Umemura, Nobuhisa Magosaki, Koji Tamura, Koshichiro Hirosawa

Department of Internal Medicine, The Heart Institute of Japan, Tokyo Women's Medical College

The purpose of this study is to evaluate criteria of left atrial overload (LAO) and right atrial overload (RAO) and to estimate the severity of mitral valve stenosis (MS) as a model of LAO, by body surface mapping (BSM) of atrial activation. Atrial BSM was recorded in 21 normal subjects (N-group), 20 cases of LAO (L-group), 11 cases of RAO (R-group) and 13 cases of MS with sinus rhythm (MS-group), by averaging method of 6 to 12 beats. In L-group, duration of left maximum (DLM) was prolonged compared with $\mathrm{N}-$ and $\mathrm{R}-$ group $(\mathrm{P}<0.01)$, and in 19 cases $(95 \%)$ of L-group DLM was more than $50 \mathrm{~ms}$. In R-group, duration of anterior maximum (DAM) was prolonged compared with $\mathrm{N}-$ and $\mathrm{L}-$ group $(\mathrm{P}<0.01)$, and in 9 cases $(82 \%)$ of R-group DAM was more than $46 \mathrm{~ms}$. Since maximal amplitude of anterior maximum (AAM) was $97 \pm 26 \mu \mathrm{V}$ in $\mathrm{N}-$ group, $94 \pm 29 \mu \mathrm{V}$ in $\mathrm{L}-$ group, and $299 \pm 91 \mu \mathrm{V}$ in $\mathrm{R}-$ group respectively, AAM over $180 \mu \mathrm{V}$ can be a criterion of RAO. In MS-group, there was no relationship between leftward components of maximum and parameters of volume and pressure study. On the other hand, AAM showed significant correlations with mean pulmonary artery pressure, diastolic pulmonary artery pressure, mitral valve pressure gradient and mitral valve area. These results suggested that severity of MS was estimable with anterior components of maximum. 